ISSN 0103-9954

\title{
FERTILIDADE DO SOLO E SUBSTÂNCIAS HÚMICAS EM ÁREA DE CAVA DE EXTRAÇÃO DE ARGILA REVEGETADA COM EUCALIPTO E LEGUMINOSAS NO NORTE FLUMINENSE
}

\author{
SOIL FERTILITY AND HUMIC SUBSTANCES IN AN AREA OF CLAY EXTRACTION \\ REVEGETATED WITH EUCALYPT AND LEGUMES IN THE NORTH OF \\ RIO DE JANEIRO STATE
}

\author{
Cristiane Figueira da Silva ${ }^{1}$ Arcângelo Loss ${ }^{2}$ Élida Ribeiro do Carmo ${ }^{3}$ Marcos Gervasio Pereira ${ }^{4}$ \\ Eliane Maria Ribeiro da Silva ${ }^{5}$ Marco Antônio Martins ${ }^{6}$
}

\section{RESUMO}

A revegetação de áreas de extração de argila com eucalipto e leguminosas pode favorecer a melhoria dos atributos químicos do solo. O objetivo do trabalho foi avaliar a influência de plantios puros e consorciados de leguminosas e eucalipto na fertilidade do solo e nos teores de carbono orgânico total e das substâncias húmicas, em uma cava de extração de argila no Norte Fluminense. O solo original da área da cava em estudo é um Cambissolo Háplico Sódico gleico, no qual a camada superficial (espessura de $20 \mathrm{~cm}$, aproximadamente), com maiores teores de matéria orgânica, foi retirada e devolvida ao fundo da cava após a extração da argila. A cava foi nivelada mecanicamente e mantida sob pousio durante dois anos. A revegetação foi realizada com as espécies Eucalyptus camaldulensis (Euc), Acacia mangium (Ac) e Sesbania virgata (Sesb), em plantios puros e consorciados. O delineamento experimental utilizado foi o de blocos casualizados com sete tratamentos (plantios puros de Euc, Ac e Sesb; plantios consorciados de Euc + Ac, Euc + Sesb, Ac + Sesb; e área degradada com vegetação espontânea (ADVE)) e três repetições. Aos 48 meses após implantação dos sistemas foram coletadas amostras de solo na camada de 0,00 a $0,05 \mathrm{~m}$, em que se avaliaram algumas variáveis da fertilidade do solo ( $\mathrm{pH}$ em água, $\mathrm{P}, \mathrm{K}^{+} ; \mathrm{Ca}^{+2}, \mathrm{Mg}^{+2}, \mathrm{Na}^{+}, \mathrm{Al}^{+3}, \mathrm{H}+\mathrm{Al}$ ), carbono orgânico total $(\mathrm{COT})$, nitrogênio $(\mathrm{N})$ e quantificado o carbono das substâncias húmicas em carbono da humina (C-HUM), carbono da fração ácido húmico (C-FAH) e ácido fúlvico (C-FAF). Observou-se que todos os plantios promoveram aumentos nos teores $\mathrm{Ca}, \mathrm{Mg}, \mathrm{P}, \mathrm{K}, \mathrm{N}, \mathrm{COT}, \mathrm{C}-\mathrm{HUM}, \mathrm{C}-\mathrm{FAH}$ e C-FAF em relação à ADVE. A revegetação de áreas de cava de extração de argila no Norte Fluminense com plantios puros ou consorciados de eucalipto e leguminosas, acarreta em melhorias da fertilidade do solo e dos teores de carbono e nitrogênio totais do solo e do carbono das substâncias húmicas. Aos quatro anos após a revegetação, os sistemas mais indicados, de uma forma geral, para acarretar em aumentos dos teores de COT, $\mathrm{N}$ total, $\mathrm{Mg}$, soma de bases e capacidade de troca catiônica, destaca-se o plantio de acácia, dentre os plantios puros, e o plantio de eucalipto + sesbânia, dentre os plantios consorciados.

1 Engenheira Florestal, Dra., Pós-Doutoranda do Curso de Pós-graduação em Ciências Ambientais e Florestais, Instituto de Florestas, Universidade Federal Rural do Rio de Janeiro, BR 465, Km 07, CEP 23890-000, Seropédica (RJ), Brasil. cfigueirasilva@yahoo.com.br

2 Engenheiro Agrônomo, Dr., Professor Adjunto do Departamento de Engenharia Rural, Centro de Ciências Agrárias, Universidade Federal de Santa Catarina, Rodovia Admar Gonzaga, 1346, CEP 88034-000, Florianópolis (SC), Brasil. arcangeloloss@yahoo.com.br

3 Engenheira Agrônoma, Mestre em Produção Vegetal, Universidade Estadual do Norte Fluminense Darcy Ribeiro, Av. Alberto Lamego, 2000, Campos dos Goytacazes, CEP 28013-602, Goytacazes (RJ), Brasil. elidacarmo@yahoo.com.br

4 Engenheiro Agrônomo, Dr., Professor Titular do Departamento de Solos, Universidade Federal Rural do Rio de Janeiro, BR 465 km 7, CEP 23890-000, Seropédica (RJ), Brasil. gervasio@ufrrj.br

5 Engenheira Florestal, Dr ${ }^{\mathrm{a}}$., Pesquisadora da Embrapa Agrobiologia, BR 465, km 7, CEP 23890-000, Seropédica (RJ), Brasil. eliane.silva@embrapa.br

6 Engenheiro Agrônomo, PhD., Professor Titular da Universidade Estadual do Norte Fluminense Darcy Ribeiro, Av. Alberto Lamego, 2.000, Campos dos Goytacazes, CEP 28013-602, Goytacazes (RJ), Brasil. marco@uenf.br

Recebido para publicação em 15/12/2010 e aceito em 20/11/2013

Ci. Fl., v. 25, n. 3, jul.-set., 2015 
Além disso, o consórcio eucalipto + sesbânia, apresentou um dos maiores teores $\mathrm{C}$ da fração humina.

Palavras-chave: bases trocáveis; carbono orgânico; recuperação.

\begin{abstract}
The revegetation of areas of clay extraction with eucalypt and legumes can promote the improvement of soil chemical atributtes. The aim of this study was to evaluate the influence of pure plantations and intercropping of legumes and eucalypt on soil fertility and the content of total organic carbon and humic substances, in a mining digging clay in North Fluminense. The original soil dig area under study is a Inceptsol where the surface layer (thickness of $20 \mathrm{~cm}$ approximately), with higher concentrations of organic matter was removed and returned to the bottom of the dig after the extraction of clay. The dig was leveled mechanically and kept under fallow for two years. Revegetation was performed with the species Eucalyptus camaldulensis (Euc), Acacia mangium (Ac) and Sesbania virgata (Sesb), in pure and intercropped. The experimental design was a randomized block design with seven treatments (pure stands of Euc, Ac and Sesb; Intercropping of Euc + Ac + Euc Sesb, Ac + Sesb, and degraded area with natural vegetation (DANV)) and three replications. At 48 months after implantation of the systems were sampled soil layer from 0.00 to 0.05 $\mathrm{m}$, which evaluated some variables of soil fertility ( $\mathrm{pH}, \mathrm{P}, \mathrm{K}^{+}, \mathrm{Ca}^{+2}, \mathrm{Mg}^{+2}, \mathrm{Na}^{+}, \mathrm{Al}^{+3}, \mathrm{H}+\mathrm{Al}$ ), total organic carbon (TOC), nitrogen $(\mathrm{N})$ and quantified the carbon of humic substances in the humin carbon (C-HUM), humic acid carbon (C-FAH ) and fulvic acid (C-FAF). It was observed that all stands promoted increases in the concentration $\mathrm{Ca}, \mathrm{Mg}, \mathrm{P}, \mathrm{K}, \mathrm{N}, \mathrm{TOC}, \mathrm{HUM} \mathrm{C}-\mathrm{C}-\mathrm{C}-\mathrm{FAF}$ and HAF relative to DANV. The revegetation of areas of mining digging clay in North Fluminense pure stands or mixed with eucalypt and legumes, leads to improvements in soil fertility and carbon and total soil nitrogen and carbon of humic substances. At four years after revegetation systems are indicated, in general, to result in increases in TOC, total $\mathrm{N}, \mathrm{Mg}$, sum of bases and cation exchange capacity, there is the planting of acacia plantations among pure, and the planting of eucalypt + sesbania, among Intercropping. In addition, the consortium eucalypt + sesbania, presented one of the highest levels of $\mathrm{C}$ humin fraction.
\end{abstract}

Keywords: exchangeable cations; organic carbon; recuperation.

\section{INTRODUÇÃO}

A extração de argila pela indústria ceramista no Norte Fluminense é uma atividade de grande importância socioeconômica para a região com geração de aproximadamente 5.000 empregos diretos e uma produção diária estimada de cerca de 5.000.000 de peças (RAMOS et al., 2003; SCHIAVO, 2005; RODRIGUES et al., 2006). Embora exerça importante papel econômico, essa atividade tem causado degradação ambiental em grande escala na região Norte Fluminense (SANTIAGO, 2005; SCHIAVO et al., 2007a).

No município de Campos dos Goytacazes - RJ, área de maior concentração de indústrias de cerâmicas, estima-se uma retirada diária de aproximadamente $7.000 \mathrm{~m}^{3}$ de solo, promovendo a degradação de uma área em torno de $3.500 \mathrm{~m}^{2}$ dia $^{-1}$ (RAMOS et al., 2003; SCHIAVO, 2005). Quando se trata de extração de argila mecanizada, a camada superficial (com maior conteúdo de matéria orgânica) é retirada e estocada. Após a retirada da argila, essa camada superficial é devolvida para o fundo da cava. Assim, grandes cavas de extração de argila são formadas, resultando na degradação da paisagem (SCHIAVO et al., 2007a).

Em alguns casos, após algum tempo de abandono da área (que pode variar de meses até décadas), inicia-se o processo de sucessão natural com gramíneas espontâneas que são imediatamente utilizadas para o pastoreio, o que aumenta de forma exponencial a degradação da área, reduzindo a capacidade de resiliência do local (RODRIGUES et al., 2006). A recuperação dessas áreas envolve, normalmente, um alto custo operacional (AUMOND e BALISTIERI, 1997; CAMPOS, 1997), devido à utilização de máquinas para aplainar a superfície da cava, reposição da camada superficial do solo e adubação para, a partir daí, ser iniciado o processo de revegetação da área (RODRIGUES et al., 2006).

A seleção de espécies adaptadas às condições adversas e capazes de melhorar o solo é fundamental para o sucesso do processo de mitigação dos efeitos negativos em áreas resultantes 
do processo de extração de argila. O plantio de espécies perenes, especialmente espécies arbóreas, pode resultar em melhoria dos atributos químicos, físicos e biológicos do solo (MENDONÇA et al., 2008a,b). Um dos processos mais viáveis do ponto de vista econômico para recuperação das cavas é a revegetação com espécies leguminosas (SCHIAVO et al., 2010), que inoculadas com os microrganismos simbiontes (rizóbio e fungos micorrízicos arbusculares), conseguem se estabelecer nessas áreas (FRANCO e FARIA, 1997). A utilização de leguminosas fixadoras de $\mathrm{N}$ de rápido crescimento tem como finalidade aumentar a disponibilidade de $\mathrm{N}$ e acelerar a ciclagem de nutrientes (FORRESTER et al., 2004; FORRESTER et al., 2005), podendo também promover o aumento do estoque de carbono no solo, bem como melhorar seus atributos químicos (VEZZANI et al., 2001; GARAY et al., 2003; SCHIAVO, 2005; MENDONÇA et al., 2008a) e favorecer a formação de substâncias húmicas no solo (SCHIAVO et al., 2009).

A leguminosa Sesbania virgata (Cav.) Pers. vem sendo destacada como de grande importância na recuperação de cavas de extração de argila, pela sua frequência de ocorrência, capacidade de se associar a bactérias fixadoras de $\mathrm{N}_{2}$ atmosférico, e pelo bom estabelecimento e crescimento nesse tipo de ambiente (SÂMOR, 1999; SCHIAVO, 2005; COUTINHO et al., 2006). Já a leguminosa arbórea Acacia mangium Willd tem se destacado pela rusticidade, pela adaptabilidade às condições adversas de solo e clima, pelo rápido crescimento e pela elevada produção de biomassa e serapilheira rica em nitrogênio, devido à fixação biológica quando em associação com rizóbio (ANDRADE et al., 2000; GALIANA et al., 2002). Essas características das leguminosas assumem grande importância em se tratando da dinâmica da matéria orgânica, bem como dos atributos químicos e físicos do solo (SCHIAVO et al., 2007a,b).

De acordo com Schiavo et al. (2010), em áreas de extração de argila, ocorre uma resistência, por parte dos ceramistas, ao plantio de leguminosas, tendo em vista, a repressão dos órgãos ambientais ao corte das espécies para o uso da madeira. Assim, o plantio de eucalipto tem tido preferência, uma vez que sua madeira é retirada normalmente (sem repressão) para que possa ser utilizada como combustível no processo de fabricação das cerâmicas. Contudo, de acordo com esses mesmos autores, o desenvolvimento do eucalipto não tem sido satisfatório em comparação a plantios comerciais em outros Estados. Dessa forma, tem sido sugerido o plantio consorciado dessas espécies com as leguminosas (SCHIAVO, 2005; COUTINHO et al., 2006, MENDONÇA et al., 2008a,b), que além de contribuírem para uma melhor nutrição e produção de biomassa do eucalipto (RODRIGUES et al., 2003; FORRESTER 2004; 2006), podem promover melhorias na qualidade do solo (MENDONÇA et al., 2008a; SILVA et al., 2012).

Diante do exposto, este trabalho teve como objetivo avaliar a influência de plantios puros e consorciados de leguminosas e eucalipto na fertilidade do solo e nos teores de carbono orgânico total e das substâncias húmicas, em uma cava de extração de argila no Norte Fluminense.

\section{MATERIAL E MÉTODOS}

O trabalho foi realizado em uma cava de extração de argila pertencente à cerâmica Stilbe Ltda., localizada no distrito de Poço Gordo

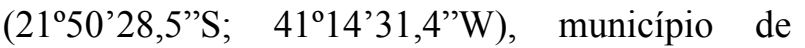
Campos dos Goytacazes - RJ, região Norte Fluminense. O clima da região é classificado, de acordo com Köppen, como Aw, tropical quente e úmido, com período seco no inverno e chuvoso no verão, e com precipitação anual em torno de 1.020 $\mathrm{mm}$. As médias de temperatura e precipitação da área em estudo, registradas no período de maio de 2006 a junho de 2007 foram de, respectivamente, $24,1^{\circ} \mathrm{C}$ e $86,6 \mathrm{~mm}$.

O solo original da área da cava em estudo é um Cambissolo Háplico Sódico gleico, com profundidade de aproximadamente $3 \mathrm{~m}$, do qual a camada superficial (Horizonte A) (espessura de $20 \mathrm{~cm}$, aproximadamente), com maiores teores de matéria orgânica $\left(19,65 \mathrm{~g} \mathrm{~kg}^{-1}\right)$ (SCHIAVO, 2005) foi retirada e devolvida ao fundo da cava após a extração da argila (agosto de 2000). A cava foi nivelada mecanicamente e mantida sob pousio durante dois anos, surgindo como vegetação espontânea a braquiária (Brachiaria mutica (Forsk.) Stapf.) (SCHIAVO, 2005). Após o período de pousio, em agosto de 2002, realizouse o preparo da área com uma aração e duas gradagens (exceto as parcelas do tratamento "área degradada com vegetação espontânea”- ADVE). A cava foi revegetada com Eucalyptus camaldulensis Dehn, Acacia mangium Willd e Sesbania virgata (Cav.) Pers. (SCHIAVO, 2005), utilizando-se um espaçamento de dois metros entre plantas e três metros entre linhas ( $2 \mathrm{~m} \times 3 \mathrm{~m})$. Realizou-se uma 
adubação nas covas (exceto na ADVE) com fosfato de rocha de Araxá (composição: 25,9\% Ca, 11,6\% P total, $5,9 \% \mathrm{P}$ disponível), sendo a dose de $100 \mathrm{mg} /$ cova.

O delineamento experimental utilizado foi o de blocos ao acaso com sete tratamentos e três repetições, sendo os tratamentos: monocultivos de Eucalyptus camaldulensis, Acacia mangium e Sesbania virgata; consórcio de Eucalyptus camaldulensis + Acacia mangium; Eucalyptus camaldulensis + Sesbania virgata; Acacia mangium + Sesbania virgata; e área degradada com vegetação espontânea (ADVE) (predomínio de Brachiaria mutica). Nos tratamentos consorciados, as linhas foram alternadas com o plantio das espécies. Entre os plantios foram alocadas duas linhas de plantas de Eucalyptus camaldulensis que constituíram a bordadura. A parcela experimental foi constituída por 16 plantas.

As espécies, em fase de produção de mudas, foram inoculadas com fungos micorrízicos arbusculares (FMAs) (Glomus macrocarpum, Glomus etunicatum e Entrophospora colombiana) isoladosde umaárea de extração de argila, pertencente à cerâmica Caco Manga Ltda., localizada no distrito de Ururaí, no município de Campos dos Goytacazes - RJ. O isolado, pertencente ao banco de inóculo do Laboratório de Solos da Universidade Estadual do Norte Fluminense (UENF), foi multiplicado em plantas de Brachiaria bryzantha em mistura de solo mais areia na proporção de 1:2 (v:v). Além dos FMAs, as leguminosas foram inoculadas (na semente) com estirpes específicas de rizóbio, sendo BR 3609, BR 6009 para Acacia mangium e BR 5401 para Sesbania virgata. Tais estirpes foram provenientes da Embrapa Agrobiologia, Seropédica - RJ.

Decorridos quatro anos da implantação das parcelas, em setembro de 2006, foram coletadas, na camada de 0,00-0,05 m, amostras de terra para avaliação dos atributos químicos. Foram coletadas em cada parcela 10 amostras simples, que misturadas, resultaram em uma amostra composta por parcela. Estas foram secas ao ar, destorroadas e passadas em peneira com malha de $2 \mathrm{~mm}$, para obtenção da terra fina seca ao ar (TFSA). As análises químicas foram realizadas de acordo com Embrapa (1997), sendo avaliados o $\mathrm{pH}$ em água; $\mathrm{P}$ disponível e $\mathrm{K}^{+} ; \mathrm{Na}^{+}, \mathrm{Ca}^{+2} \mathrm{e} \mathrm{Mg}^{+2}$ trocáveis. $\mathrm{O}$ nitrogênio foi determinado automaticamente via combustão seca (CHN/S ANALYSER-PERKYN ELMER modelo PE 2400-II). Também foi calculada a soma de bases (SB) trocáveis e a capacidade troca catiônica (CTC efetiva).

A quantificação do carbono orgânico total (COT) foi realizada segundo Yeomans e Bremmer (1988). Para a realização do fracionamento químico da matéria orgânica do solo (MOS), no qual se quantificou o carbono das frações humina (C-HUM), ácidos húmicos (C-FAH) e ácidos fúlvicos (C-FAF), foram procedidas as análises de acordo com o método proposto pela Sociedade Internacional de Substâncias Húmicas (IHSS) (SWIFT, 1996), com adaptações propostas por Benites et al. (2003). Pesou-se uma massa de solo igual a $1,0 \mathrm{~g}$, submetendo-se ao contato com 20 $\mathrm{mL}$ de $\mathrm{NaOH} 0,1 \mathrm{~mol} \mathrm{~L}^{-1}$ por 24 horas. A separação entre o extrato alcalino $(\mathrm{EA}=\mathrm{C}-\mathrm{FAF}+\mathrm{C}-\mathrm{FAH})$ e o resíduo (C-HUM) foi feita por centrifugação a $7800 \mathrm{rpm}$ por 30 minutos. Seguiu-se mais uma lavagem com a solução $20 \mathrm{~mL}$ de $\mathrm{NaOH} 0,1 \mathrm{~mol}$ $\mathrm{L}^{-1}$ e centrifugação. Posteriormente, reuniram-se os dois extratos obtidos após as centrifugações, resultando em volume final de aproximadamente 40 $\mathrm{mL}$. O resíduo foi retirado dos tubos da centrífuga, acondicionados em placa de petri e secos a $65^{\circ} \mathrm{C}$ (secagem completa). $\mathrm{O} \mathrm{pH}$ do EA foi ajustado a 1,0 $( \pm 0,1)$ com $\mathrm{H}_{2} \mathrm{SO}_{4} 20 \%$, seguido de decantação por 18 horas em geladeira. O precipitado (C-FAH) foi separado da fração solúvel (C-FAF) por filtragem e ambos os volumes aferidos a $50 \mathrm{~mL}$, com água destilada.

A quantificação do carbono orgânico nas frações C-FAF e C-FAH foi feita usandose alíquotas de 5,0 mL de extrato, $1,0 \mathrm{~mL}$ de dicromato de potássio $0,042 \mathrm{~mol} \mathrm{~L}^{-1}$ e $5,0 \mathrm{~mL}$ de $\mathrm{H}_{2} \mathrm{SO}_{4}$ concentrado, em bloco digestor a $150^{\circ} \mathrm{C}$ (30 min) e titulação com sulfato ferroso amoniacal $0,0125 \mathrm{~mol} \mathrm{~L}^{-1}$. No resíduo seco em estufa, foi determinado o C-HUM, adicionando-se $5,0 \mathrm{~mL}$ de dicromato de potássio $0,1667 \mathrm{~mol} \mathrm{~L}^{-1}$ e $10,0 \mathrm{~mL}$ de $\mathrm{H}_{2} \mathrm{SO}_{4}$ concentrado, em bloco digestor a $150^{\circ} \mathrm{C}$ (30 min) e titulação com sulfato ferroso amoniacal $0,25 \mathrm{~mol} \mathrm{~L}^{-1} \mathrm{e}$ indicador ferroin (YEOMANS e BREMNER, 1988).

Os dados provenientes das análises químicas das amostras foram avaliados quanto à homocedastia, pelo teste de Cochran (SNEDECOR e COCHRAN, 1989), e distribuição normal dos resíduos, pelo teste de Lilliefors (CAMPOS, 1979). Posteriormente, foram submetidos à análise de variância e ao teste $\mathrm{t}$ (LSD) a $5 \%$ de probabilidade. As relações entre os atributos edáficos foram determinadas por análise de correlação de Pearson. Estes testes e análises foram 
realizados com o auxílio dos programas estatísticos SAEG-5.0 e SISVAR-5.0.

\section{RESULTADOS E DISCUSSÃO}

\section{Fertilidade do solo}

Ao se compararem as características químicas das áreas sob os plantios e a ADVE, verificou-se que houve alterações significativas da fertilidade do solo (Tabela 1). Padrão semelhante foi observado por Batista (2006), Paulucio (2007) e Mendonça et al. (2008a), em plantios puros e consorciados de leguminosas e eucalipto, em cava de extração argila, cujo solos, antes da exploração, eram Cambissolos Háplicos Gleicos sódicos.

Os valores de $\mathrm{pH}$ variaram de 4,88 (plantio com acácia) a 6,82 (ADVE). Todos os plantios, à exceção do plantio puro de eucalipto, promoveram uma redução nos valores de $\mathrm{pH}$, em relação à ADVE (Tabela 1). Mishra et al. (2003) observaram decréscimo no valor de $\mathrm{pH}$ do solo (solo salino) sob plantio puro de Eucalyptus tereticornis aos três, seis e nove anos de idade, enquanto Leite (2001) verificou valores mais baixos de $\mathrm{pH}$ em áreas de plantios de eucalipto, em relação ao de pastagem. Por outro lado, Batista (2006) e Mendonça et al. (2008) observaram aumento no valor de $\mathrm{pH}$, após 24 e 36 meses, respectivamente, em resposta a plantios puros e consorciados de Mimosa caesalpiniifolia (sabiá) e Eucalyptus spp, em cava de extração de argila. Resultados similares foram observados por Santiago (2005) para plantios consorciados de sesbânia com Eucalyptus robusta e de sesbânia com Eucalyptus tereticornis, após um ano de plantio, nesse mesmo tipo de ambiente.

Avaliando as características químicas de uma área em recuperação com plantios de Acacia mangium e Eucalyptus pellita, aos oito anos de idade, Franco et al. (1995) encontraram valores de $\mathrm{pH}$ menores no plantio da leguminosa em relação ao do eucalipto. Este padrão foi atribuído à capacidade da leguminosa em se associar com bactérias fixadoras de $\mathrm{N}_{2}$ atmosférico, o que faz com que ocorra uma maior extrusão de prótons e uma consequente redução do $\mathrm{pH}$. Fato que pode explicar os menores valores de $\mathrm{pH}$, observado neste estudo, nos solos sob os plantios com as leguminosas em relação ao plantio puro de eucalipto.

Para os teores de $\mathrm{Al}^{+3}$ verificou-se que somente o plantio puro de eucalipto não promoveu a redução do conteúdo desse elemento quando comparado à área ADVE (Tabela 1). Os valores de $\mathrm{Al}^{+3}$ encontrados foram muito baixos, o que confirma a baixa presença de acidez trocável. Estes dados são corroborados pelos de Mendonça (2006) em plantios puros e consorciados de Eucalyptus spp. e sabiá, em cava de extração de argila no Norte Fluminense. Por outro lado, no que tange à acidez potencial $(\mathrm{H}+\mathrm{Al})$, os plantios proporcionaram um aumento, em relação à ADVE. Em estudo realizado em área degradada pela

TABELA 1: Caracterização química da camada $0,00-0,05 \mathrm{~m}$ do solo de cava de extração de argila com vegetação espontânea (ADVE) e revegetada com Eucalyptus camaldulensis (Euc), Acacia mangium (Ac) e Sesbania virgata (Ses) em plantios puros e consorciados.

TABLE 1: Chemical characterization of the 0,00-0,05 $\mathrm{m}$ soil layer from an area of clay mining under spontaneous vegetation (ADVE) and revegetated with Eucalyptus camaldulensis (Euc), Acacia mangium (Ac) and Sesbania virgata (Ses) in pure and mixed stands.

\begin{tabular}{|c|c|c|c|c|c|c|c|c|c|c|}
\hline Sistemas & $\mathrm{pH}$ & $\mathrm{Ca}$ & $\mathrm{Mg}$ & $\mathrm{Na}$ & $\mathrm{Al}$ & $\mathrm{H}+\mathrm{Al}$ & SB & $\mathrm{CTC}_{\mathrm{pH} 7,0}$ & K & $\mathrm{P}$ \\
\hline \multicolumn{9}{|c|}{ - } & \multicolumn{2}{|c|}{$\mathrm{mg} \mathrm{kg}^{-1}$} \\
\hline Euc & $5,64 \mathrm{a}$ & $6,20 \mathrm{~b}$ & $4,12 \mathrm{ab}$ & $1,52 \mathrm{c}$ & $0,10 \mathrm{a}$ & $2,86 \mathrm{~b}$ & $13,06 \mathrm{ab}$ & $15,92 \mathrm{~b}$ & $477,50 \mathrm{~b}$ & 65,77 a \\
\hline Ac & $4,88 \mathrm{c}$ & $5,51 \mathrm{~b}$ & $5,02 \mathrm{a}$ & $2,78 \mathrm{a}$ & $0,00 \mathrm{c}$ & $4,62 \mathrm{a}$ & $14,08 \mathrm{ab}$ & 18,39 a & $378,33 \mathrm{c}$ & $26,63 \mathrm{~b}$ \\
\hline Ses & $5,11 \mathrm{bc}$ & $5,90 \mathrm{~b}$ & $4,64 \mathrm{a}$ & $1,63 \mathrm{c}$ & $0,07 \mathrm{~b}$ & $4,70 \mathrm{a}$ & $12,93 \mathrm{ab}$ & $17,64 \mathrm{ab}$ & $297,50 \mathrm{~d}$ & $22,21 \mathrm{~cd}$ \\
\hline $\mathrm{Euc}+\mathrm{Ac}$ & $5,58 \mathrm{~b}$ & $7,86 \mathrm{a}$ & $4,83 \mathrm{a}$ & $0,63 \mathrm{~d}$ & $0,00 \mathrm{c}$ & $3,14 \mathrm{~b}$ & $14,76 \mathrm{a}$ & $17,90 \mathrm{a}$ & $570,00 \mathrm{a}$ & $20,70 \mathrm{~cd}$ \\
\hline Euc + Ses & $5,43 \mathrm{bc}$ & $5,53 \mathrm{~b}$ & $4,78 \mathrm{a}$ & $2,37 \mathrm{~b}$ & $0,00 \mathrm{c}$ & $4,08 \mathrm{a}$ & $13,43 \mathrm{ab}$ & $17,51 \mathrm{ab}$ & $270,00 \mathrm{~d}$ & $23,65 \mathrm{bc}$ \\
\hline $\mathrm{Ac}+\mathrm{Ses}$ & $5,20 \mathrm{bc}$ & $7,55 \mathrm{a}$ & $3,46 \mathrm{~b}$ & $0,50 \mathrm{~d}$ & $0,00 \mathrm{c}$ & $4,66 \mathrm{a}$ & $12,27 \mathrm{~b}$ & $16,93 \mathrm{ab}$ & $280,00 \mathrm{~d}$ & $20,60 \mathrm{~d}$ \\
\hline ADVE & $6,82 \mathrm{a}$ & $3,85 \mathrm{c}$ & $2,48 \mathrm{c}$ & $2,59 \mathrm{ab}$ & $0,10 \mathrm{a}$ & $0,95 \mathrm{c}$ & $9,31 \mathrm{c}$ & $10,26 \mathrm{c}$ & $155,00 \mathrm{e}$ & $14,66 \mathrm{e}$ \\
\hline
\end{tabular}

Em que: médias seguidas de mesma letra na coluna não diferem pelo teste $\mathrm{t}$ (LSD) a $5 \%$. CTC $=$ capacidade de troca catiônica a pH 7,0. 
extração de bauxita, em Porto Trombetas (PA), após quatro anos de revegetação com a espécie Acacia holosericea, foi observado que a maior concentração de matéria orgânica do solo resultou em maiores valores de $\mathrm{H}+\mathrm{Al}$ (OLIVEIRA et al., 2000). No presente estudo foi observada correlação positiva e significativa entre os teores de COT e a acidez potencial do solo $(\mathrm{r}=0,74, \mathrm{P}=0,03)$.

Em relação aos teores de $\mathrm{P}$ e K, verificouse que todos os plantios promoveram aumentos destes elementos em relação à ADVE, chegando a ser observado um aumento de $350 \%$ nos teores de $\mathrm{P}$ na área de plantio puro de eucalipto e aumentos de $200 \%$ de $\mathrm{K}$ na área de plantio consorciado de eucalipto e acácia (Tabela 1). Esses resultados podem ser decorrentes da associação dos fungos micorrízicos arbusculares (FMAs) com o sistema radicular das espécies avaliadas, favorecendo a exploração dos nutrientes em maiores profundidades. Dessa forma, com a decomposição e ciclagem dos nutrientes contidos na serapilheira $(\mathrm{Euc}+\mathrm{Ac}=$ 11,$4 ; \mathrm{Ac}=8,3 ; \mathrm{Ac}+\mathrm{Ses}=6,9 ; \mathrm{Euc}=6,3 ; \mathrm{Ses}+\mathrm{Euc}$ $=5,9$ e Ses $=3,5 \mathrm{Mg} \mathrm{ha}^{-1} \mathrm{ano}^{-1}$, respectivamente, segundo Silva (2009)), parte dos nutrientes absorvidos são devolvidos ao solo. Os maiores teores de $\mathrm{K}$ encontrados no tratamento Euc + Ac estão associados à maior deposição de serapilheira neste tratamento em relação aos demais. Para o P, os maiores teores encontrados no eucalipto podem ser decorrentes do efeito benéfico das micorrizas na aquisição do P, pois, segundo Grove et al. (1996), o $P$ é limitado em florestas de eucalipto. Em relação à $\mathrm{ADVE}$, os menores valores de $\mathrm{P}$ e $\mathrm{K}$, podem ser em função da menor abundância total e diversidade de espécies da fauna do solo, bem como pela menor diversidade dos FMAs encontrados na ADVE em comparação aos demais tratamentos (SILVA et al., 2010; SILVA et al., 2012; SILVA et al., 2013).

Batista (2006) observou que plantios puros e consorciados de diferentes espécies de eucalipto e sabiá, em cava de extração de argila, proporcionaram aumentos significativos nos teores de $\mathrm{P}$ e de $\mathrm{K}$ no solo, quando comparados à área com vegetação espontânea. Entre os plantios foram observados menores teores de $\mathrm{K}$ no solo naqueles sob plantio de sesbânia (puro e consorciado) (Tabela 1).

Para os teores de $\mathrm{Ca}$ e o $\mathrm{Mg}$, assim como indiretamente para os valores de soma de bases (SB), foram observadas diferenças significativas, tanto entre os plantios, quanto entre estes e a ADVE (Tabela 1). No caso do Ca, os maiores valores foram verificados nas áreas dos plantios consorciados de eucalipto com acácia e de acácia com sesbânia, e os menores na ADVE (Tabela 1). Em relação ao $\mathrm{Mg}$, o plantio consorciado de acácia + sesbânia apresentou menor teor em relação à maioria dos plantios, sendo semelhante apenas ao plantio puro do eucalipto. Todos os plantios promoveram incrementos nos teores desse elemento quando comparados à ADVE (Tabela 1).

De maneira geral, os sistemas consorciados favorecem maior aporte de $\mathrm{Ca}$ ao solo (exceção Euc+Ses) quando comparado com os sistemas puros. Esse padrão pode ser decorrente da qualidade da serapilheira e do aumento da diversidade da fauna do solo e dos FMAs (SILVA, 2009). Para o $\mathrm{Mg}$, o consórcio com somente leguminosas está acarretando no maior uso do $\mathrm{Mg}$ pelas leguminosas em comparação aos demais sistemas consorciados e puros. Segundo Barros et al. (1986), a eficiência do uso de um nutriente pela planta aumenta à medida que esse nutriente diminui no solo. Silva (2009) encontrou maior eficiência no uso do $\mathrm{Mg}$ no consórcio de Ac + Ses em comparação aos demais tratamentos. Em relação à ADVE, os menores teores de $\mathrm{Ca}$ e $\mathrm{Mg}$ podem estar associados às diferenças na quantidade de serapilheira aportada ao solo, bem como a menor abundância total e diversidade de espécies da fauna do solo, o que provavelmente reduz as taxas de decomposição e consequente liberação dos nutrientes para o solo.

Em relação ao $\mathrm{Na}$, observou-se uma redução nos teores no solo sob a maioria dos plantios, em comparação à área com vegetação espontânea. Os consórcios de eucalipto com acácia e acácia + sesbânia foram aqueles que apresentaram os menores valores (Tabela 1). Mendonça et al. (2008) observaram redução nos teores de $\mathrm{Na}$ em plantios puros de Eucalyptus tereticornis e de sabiá. Os menores teores encontrados nas áreas de plantio podem ser decorrentes de uma maior lixiviação de íons, devido à melhoria da agregação do solo proporcionado pelas raízes ou ainda, do acúmulo de Na pelas plantas (MISHRA et al., 2003).

Quanto à SB, a área ADVE foi inferior em relação aos plantios. Enquanto entre os plantios só houve diferença entre o consórcio de eucalipto + acácia e de acácia + sesbânia, tendo este último plantio apresentado os menores valores (Tabela 1 ). As diferenças encontradas são decorrentes dos maiores teores de $\mathrm{Ca}$ no tratamento Euc + Ac e menores de $\mathrm{Mg}$ no consórcio com leguminosas. Assim, verifica-se que o consórcio do eucalipto com uma 
leguminosa é mais vantajoso do que somente com leguminosas para o aumento das bases trocáveis em áreas de recuperação de cavas de extração de argila. Gama-Rodrigues et al. (2008) observaram valores estatisticamente iguais em relação à $\mathrm{SB}$, em solos sob Corymbia citriodora e Acacia auriculiformis, no Norte do Estado do Rio de Janeiro. Enquanto Garay et al. (2003) detectaram valores mais baixos em solos sob plantio de Eucalyptus grandis em relação ao plantio de Acacia mangium.

A capacidade de troca catiônica (CTC) variou tanto entre os plantios, quanto entre estes e a ADVE. Maiores valores foram encontrados nos plantios consorciados de eucalipto + acácia e, no monocultivo de acácia, em relação aos demais. Todos os plantios promoveram aumentos significativos na CTC, em relação à ADVE (Tabela 1). Em estudo realizado no Norte do Estado do Rio de Janeiro, Gama-Rodrigues et al. (2008) observaram um decréscimo na CTC do solo sob plantio de Acacia auriculiformis em relação à área de pasto e capoeira. Santiago (2005), em plantios puros e consorciados de eucalipto com sesbânia, em cava de extração de argila, detectou redução da CTC na maioria dos tratamentos, em relação à área anteriormente ao plantio, enquanto Mendonça (2006) não observou alterações significativas para este atributo. A CTC dos solos nesse estudo foi significativamente correlacionada com o COT do solo $(\mathrm{r}=0,79 ; \mathrm{P}=0,02)$. Esse padrão pode ser devido à predominância de argilominerais de baixa atividade, nos quais a fração orgânica contribui com a maior proporção de cargas negativas, confirmando os relatos de Araújo et al. (2007) e Silva e Resck (1997). De acordo com Silva et al. (2007), a CTC representa o poder de retenção (adsorção) de cátions, favorecendo a manutenção da fertilidade por um período prolongado de tempo.

A contribuição da vegetação em relação aos nutrientes no solo deve ser considerada, principalmente, quando as espécies florestais são submetidas à exploração (MAFRA et al., 2008). Esse é o caso da área em estudo, na qual as árvores de eucalipto e acácia, futuramente, serão submetidas a cortes, para posterior utilização da madeira como lenha, para produção de cerâmica. Essa consideração é importante, visto que, além dos nutrientes, o carbono também é removido, o que pode influenciar nos teores de matéria orgânica do solo. Assim, em caso de remoção, inclusive, dos resíduos florestais, cuidados extras devem ser tomados no planejamento do manejo florestal, no que se refere à garantia das condições da fertilidade, principalmente, em ambientes com baixa reserva de nutrientes, assegurando-se, desta forma, o desenvolvimento vegetal e a produtividade da floresta (CHAVES e CORRÊA, 2005; MAFRA et al., 2008).

\section{Carbono orgânico e nitrogênio total do solo}

Os teores de COT do solo variaram de 11,92 a 34,41 $\mathrm{g} \mathrm{kg}^{-1}$, sendo o menor valor encontrado na ADVE e o maior, na área de consórcio de eucalipto + sesbânia (Tabela 2). Todos os sistemas de plantio proporcionaram um aumento nos teores de COT no solo quando comparado à ADVE. Esses aumentos foram de $65 \%, 104 \%, 115 \%, 132 \%$, $145 \%$ e $189 \%$ respectivamente, para os plantios de eucalipto + acácia, sesbânia, acácia, eucalipto, acácia + sesbânia e eucalipto + sesbânia (Tabela 2). A adição de material orgânico proveniente principalmente da serapilheira é responsável pelo acúmulo de carbono na camada superficial do solo, à medida que a mesma vai sendo decomposta $\mathrm{e}$ humificada (MAFRA et al., 2008). A contribuição destes plantios (do presente estudo) com serapilheira, aos quatro anos de idade, para o acúmulo de matéria orgânica no solo variou de 3,5 a $11,4 \mathrm{Mg} \mathrm{ha}^{-1}$ de matéria seca ao ano (SILVA, 2009). Mendonça et al. (2008) avaliando as características químicas de substrato de cava de extração de argila, antes e após 24 meses de revegetação com plantio puro de Mimosa caesalpiniifolia Benth e consorciado com Eucalyptus robusta e Eucalyptus camaldulensis, também observaram aumento no teor de COT do solo. Estes autores destacaram que nem todos os plantios proporcionaram aumentos no teor de COT do solo como, por exemplo, plantios consorciados de sabiá com Eucalyptus tereticornis ou com Eucalyptus pellita. Supõe-se no referido trabalho que a serapilheira formada por estas duas associações apresentou maior taxa de decomposição em relação às combinações de sabiá com Eucalyptus robusta e Eucalyptus camaldulensis, resultando, desta forma, em menor acúmulo de COT no solo.

Entre os plantios puros avaliados, a área de plantio de eucalipto apresentou maiores teores de COT quando comparada com a área de plantio de sesbânia, enquanto na área com acácia observaram-se teores de COT estatisticamente iguais aos das áreas com plantios de eucalipto e sesbânia (Tabela 2). Na área com plantio de eucalipto verificou-se aumento no conteúdo COT 
em torno de 13,34\% em relação à área com plantio de sesbânia. Essa diferença pode estar relacionada com a maior produção de biomassa pelo eucalipto em relação à sesbânia $\left(6,3 \mathrm{Mg} \mathrm{ha}^{-1}\right.$ e $3,5 \mathrm{Mg} \mathrm{ha}^{-1}$ respectivamente) (SILVA, 2009), bem como pela taxa de decomposição de serapilheira. Paulucio (2007) avaliando a velocidade de decomposição do material vegetal de cada tratamento, nesse mesmo experimento, 26 meses após o plantio, observou que o material foliar de eucalipto $(\mathrm{k}=0,0018)$ apresentou menor velocidade de decomposição em relação ao da sesbânia $(\mathrm{k}=0,0025)$. Este padrão pode explicar os maiores teores de COT sob plantio de eucalipto, visto que, de acordo com GamaRodrigues et al. (1999), geralmente, em solos com similarcomposição granulométrica, uma serapilheira mais facilmente decomponível resultará em menor acúmulo de carbono, que outra com substâncias mais resistentes à decomposição. Variações nos teores de carbono orgânico sob diferentes coberturas vegetais têm sido observadas por outros autores em áreas de mineração (CARNEIRO et al. 2008; MAFRA et al., 2008).

Entre os plantios consorciados, o maior teor de COT foi observado na área com eucalipto + sesbânia, seguido de acácia + sesbânia e por fim, eucalipto + acácia (Tabela 2). Nessas áreas, segundo Silva (2009), a contribuição da serapilheira foi de 5,9; 6,9 e 11,4 $\mathrm{Mg} \mathrm{ha}^{-1}$ ano $^{-1}$, respectivamente. Vale ressaltar que o plantio consorciado de acácia
+ eucalipto, embora tenha apresentado maior taxa de deposição de serapilheira $\left(11,4 \mathrm{Mg} \mathrm{ha}^{-1} \mathrm{ano}^{-1}\right)$, foi o plantio no qual se observou, dentre todos os demais avaliados (puros e consorciados), o menor conteúdo de COT (Tabela 2). Assim, menores teores de COT neste plantio podem estar relacionados à qualidade do material vegetal (menor relação $\mathrm{C} / \mathrm{N}$ ) (PAULUCIO, 2007) depositado ao solo, associado a uma melhor atividade microbiana. De acordo com Stevenson (1982), o conteúdo de COT no solo não se deve somente à quantidade de resíduos adicionados, mas também à atividade microbiana. Assim, menores teores deste elemento no solo, podem ser atribuídos possivelmente ao aumento da atividade microbiana, causada por melhores condições de aeração, temperatura mais elevada e alternância mais frequente de umedecimento e secagem, propiciados pela maior deposição de material vegetal ao solo.

No tocante à influência do tipo de cultivo nos teores de COT, com ênfase na sesbânia, observou-se que quando em plantio puro, o sistema acumula menos COT no solo em comparação ao consórcio com a acácia e com o eucalipto (Tabela 2). Este padrão pode estar relacionado tanto à menor quantidade de serapilheira depositada pelo plantio puro (3,5 $\mathrm{Mg} \mathrm{ha}^{-1}$ ano $\left.^{-1}\right)$ (SILVA, 2009), quanto à taxa de decomposição. Segundo Paulucio (2007), na mesma área de estudo, aos 26 meses de idade, observaram-se maiores taxas de decomposição da

TABELA 2: Teores de carbono orgânico total (COT), nitrogênio total ( $\mathrm{N}$ total) e relação carbono:nitrogênio (Relação C:N), na camada de 0,00-0,05 m de solo de cava de extração de argila com vegetação espontânea (ADVE) e revegetada com Eucalyptus camaldulensis (Euc), Acacia mangium (Ac) e Sesbania virgata (Ses) em plantios puros e consorciados.

TABLE 2: Total organic carbon (TOC), total nitrogen ( $\mathrm{N}$ total) and relation carbon: nitrogen (Relation $\mathrm{C}: \mathrm{N}$ ) in the $0,00-0,05 \mathrm{~m}$ soil from an area of clay mining under spontaneous vegetation (ADVE) and revegetated with Eucalyptus camaldulensis (Euc), Acacia mangium (Ac) and Sesbania virgata (Ses) in pure and mixed plantings.

\begin{tabular}{llcl}
\hline \multirow{2}{*}{ Sistemas } & \multicolumn{2}{c}{ COT } & Relação C:N \\
\cline { 2 - 3 } & & $\mathrm{g} \mathrm{kg}^{-1}$ & $14,34 \mathrm{bc}$ \\
Euc & $27,60 \mathrm{bc}$ & $1,50 \mathrm{~cd}$ & $14,63 \mathrm{bc}$ \\
Ac & $25,67 \mathrm{~cd}$ & $1,90 \mathrm{a}$ & $13,93 \mathrm{c}$ \\
Ses & $24,35 \mathrm{~d}$ & $1,75 \mathrm{abc}$ & $14,22 \mathrm{bc}$ \\
Euc + Ac & $19,61 \mathrm{e}$ & $1,40 \mathrm{~d}$ & $18,22 \mathrm{ab}$ \\
Euc + Ses & $34,41 \mathrm{a}$ & $1,80 \mathrm{ab}$ & $20,22 \mathrm{ab}$ \\
Ac + Ses & $29,25 \mathrm{~b}$ & $1,60 \mathrm{bcd}$ & $23,83 \mathrm{a}$ \\
ADVE & $11,92 \mathrm{f}$ & $0,50 \mathrm{e}$ &
\end{tabular}

Em que: médias seguidas de mesma letra na coluna não diferem pelo teste t (LSD) a 5\%. 
serapilheira foliar de sesbânia em plantio puro, do que quando em consórcio com a acácia e com o eucalipto.

Os maiores teores de COT nos plantios puros e consorciados em detrimento a área testemunha (ADVE) (Tabela 2) indicam que o plantio de espécies arbóreas é eficiente em um primeiro aspecto da reabilitação, que segundo Moraes et al. (2008) é a melhoria da qualidade do solo. Essa etapa é de suma importância para que o processo sucessional tenha condições de se estabelecer.

Para os teores de $\mathrm{N}$ total observaram-se que os plantios puros e consorciados promoveram aumentos no conteúdo de $\mathrm{N}$ de $200 \%, 280 \%, 250 \%$, $180 \%, 260 \%, 220 \%$, respectivamente para os plantios de eucalipto, acácia, sesbânia, eucalipto + acácia, eucalipto + sesbânia e acácia + sesbânia, em relação à ADVE (Tabela 2).

Quando se comparam os teores de N entre os plantios, observou-se que o plantio puro de acácia apresentou valores significativamente maiores que o plantio puro de eucalipto e os plantios consorciados de acácia + eucalipto e acácia + sesbânia (Tabela 2). Considerando que as leguminosas são espécies fixadoras de $\mathrm{N}_{2}$ atmosférico, essas podem ter contribuído para uma maior adição desse elemento ao solo. Além disso, em solos de baixa fertilidade, mas com cobertura vegetal rica em $\mathrm{N}$, como as leguminosas, espera-se uma menor quantidade de $\mathrm{N}$ imobilizado pela biomassa microbiana, pois este elemento estará em quantidade suficiente para atender à atividade metabólica dos microrganismos e ao processo de decomposição da matéria orgânica (GAMA-RODRIGUES et al., 1997).

Maior teor de $\mathrm{N}$ total em áreas com plantio das leguminosas bracatinga (Mimosa scabrella) e feijão guandu (Cajanus cajan) foi observado por Carneiro et al. (2008) quando compararam essas áreas com plantios de eucalipto, em áreas de mineração de bauxita. Em plantios de reabilitação em áreas de mineração de bauxita, Ward (2000) observou que a utilização de leguminosas, como a bracatinga, aumentou o teor de $\mathrm{N}$ total após nove anos de idade, sendo adicionados por meio de resíduos vegetais, $300 \mathrm{~kg} \mathrm{ha}^{-1} \mathrm{ano}^{-1}$ de $\mathrm{N}$, enquanto em área próxima reabilitada com eucalipto, a adição de $\mathrm{N}$ foi em torno de $63 \mathrm{~kg} \mathrm{ha}^{-1} \mathrm{ano}^{-1}$. No presente estudo, quantidades menores de $\mathrm{N}$ foram adicionadas pelos plantios, sendo que os valores variaram de 35,06 (plantio puro de eucalipto) a 77,19 $\mathrm{kg} \mathrm{ha}^{-1} \mathrm{ano}^{-1} \mathrm{de}$
N (consórcio de acácia + eucalipto) (SILVA, 2009).

Os valores da relação $\mathrm{C}: \mathrm{N}$ para as áreas amostradas nesse estudo variaram entre 23,83 a 13,92, sendo observados maiores valores para a ADVE e menores na área com plantio de sesbânia. Entre os demais plantios não foram verificadas diferenças significativas (Tabela 2). De acordo com Moreira e Siqueira (2002), a relação C:N é considerada estabilizada quando seus valores estão situados entre 8:1 e 12:1. No presente estudo, as relações encontram-se acima deste intervalo, o que pode significar que a qualidade dos resíduos está proporcionando imobilização de matéria orgânica.

É importante ressaltar que incrementos de $\mathrm{N}$, seja por fixação biológica (leguminosas) ou adubação nitrogenada, favorecem o acúmulo de carbono no solo (BAYER e MIELNICZUK, 1997; URQUIAGA et al., 2005). Segundo Pillon et al. (2004), a incorporação de material vegetal em maiores profundidades no perfil do solo pelas raízes constitui-se em estratégia importante para melhoria da qualidade do solo em subsuperfície e para o acúmulo de carbono no solo. E, para este acúmulo de carbono, certamente o $\mathrm{N}$ exerce papel preponderante, pois não ocorre aumento de carbono no solo se a quantidade de $\mathrm{N}$ for limitante à produtividade biológica (URQUIAGA et al., 2005). Dessa forma, verifica-se que na ADVE os menores valores de $\mathrm{N}$ passam a ser limitantes para a atividade biológica (corroborando com a menor abundância total e diversidade de espécies da fauna do solo e de FMAs, neste mesmo experimento, conforme Silva et al. (2010), Silva et al. (2012) e Silva et al. 2013), não acarretando em maiores aumentos aumentos do carbono se comparado aos demais tratamentos que apresentaram três vezes mais $\mathrm{N}$ que a ADVE (Tabela 2).

\section{Carbono das substâncias húmicas do solo}

Todas as frações húmicas (ácidos fúlvicos, ácidos húmicos e humina) apresentaram maiores teores nos plantios puros e consorciados quando comparados à ADVE (Tabela 3). Este padrão é corroborado pelos maiores teores de COT encontrados nessas áreas (Tabela 2), demonstrando o efeito positivo do aporte de matéria orgânica ao solo via deposição de serapilheira para posterior formação das substâncias húmicas. Com a decomposição da serapilheira têm sido observadas alterações nas frações humificadas da MOS (CANELLAS et al., 2004; SCHIAVO, 2005). 
Como todos os sistemas propiciaram aumentos de carbono das substâncias húmicas, a revegetação dessas áreas de extração de argila com leguminosas e eucalipto acarretará na recuperação das mesmas, principalmente no tocante aos atributos edáficos. Segundo Stevenson (1994), as substâncias húmicas são responsáveis por diversos efeitos no solo, sendo destacado seu papel em solos tropicais e subtropicais altamente intemperizados devido à importância no fornecimento de nutrientes às culturas, na retenção de cátions, na complexação de elementos tóxicos e de micronutrientes, na estabilidade dos agregados, na infiltração e retenção de água, na aeração e na atividade e diversidade microbiana, constituindo assim, um componente fundamental da sua capacidade produtiva.

Entre os plantios puros, para o $\mathrm{C}$ da fração ácidos fúlvicos (C-FAF) e o $\mathrm{C}$ da fração ácidos húmicos $(\mathrm{C}-\mathrm{FAH})$ verificaram-se maiores teores na área com acácia, e para o $\mathrm{C}$ da humina (C-HUM), na área com eucalipto. Já para os plantios consorciados, os maiores teores de C-FAF foram encontrados nas áreas de eucalipto + acácia e eucalipto + sesbânia, e para o C-FAH e C-HUM, na área com eucalipto + sesbânia, e acácia + sesbânia para C-HUM (Tabela 3). Essas diferenças, observadas entre os sistemas de plantios puros e consorciados, demonstram que o carbono das substâncias húmicas
(Tabela 3), assim como o COT (Tabela 2), para as condições do presente estudo, são eficientes para identificar modificações decorrentes dos sistemas utilizados nas áreas de cava de extração de argila, principalmente quando comparados com a ADVE. Resultados semelhantes a esses são relatados por Loss et al. (2010), nos quais os autores quantificaram o carbono das substâncias húmicas de um Argissolo Vermelho-Amarelo em sistemas orgânicos de produção com diferentes coberturas vegetais e, concluíram que o fracionamento químico da MOS é uma ferramenta útil para identificar mudanças provenientes de sistemas de uso do solo e estações do ano sob manejo orgânico.

O maior percentual de carbono foi observado na fração humina, seguido da fração ácido húmico e ácidos fúlvicos, em todos os sistemas avaliados, tendo todos eles apresentado valores da relação C-EA:C-HUM, menores que 1 (Tabela 3), ou seja, um predomínio da fração humina sobre as demais frações (C-FAF e C-FAH). Esses resultados estão em consonância com os observados por Fontana et al. (2006) e Moraes et al. (2008) ao avaliarem essa relação em diferentes classes de solos (Latossolo Vermelho, Neossolos Flúvicos e Argissolos). Leite et al. (2003) verificaram percentuais da fração humina, em Argissolo, que variaram de 50 a $60 \%$, enquanto Loss et al. (2010)

TABELA 3: Carbono das frações ácidos fúlvicos, ácidos húmicos, humina e relações entre o carbono das substâncias húmicas na camada de 0,00-0,05 m de solo de cava de extração de argila com vegetação espontânea (ADVE) e revegetada com Eucalyptus camaldulensis (Euc), Acacia mangium (Ac) e Sesbania virgata (Ses) em plantios puros e consorciados.

TABLE 3: Carbon of fulvic acid, humic acids, humin and relations between the carbon of humic substances in the $0,00-0,05 \mathrm{~m}$ soil natural vegetation (ADVE) and revegetated with Eucalyptus camaldulensis (Euc), Acacia mangium (Ac) and Sesbania virgata (Ses) in pure and mixed plantings.

\begin{tabular}{|c|c|c|c|c|c|}
\hline \multirow{2}{*}{ Sistemas } & C-FAF & C-FAH & C-HUM & \multirow{2}{*}{ C-FAH/C-FAF } & \multirow{2}{*}{ EA/C-HUM } \\
\hline & \multicolumn{3}{|c|}{$\mathrm{g} \mathrm{kg}^{-1}$} & & \\
\hline Euc & $1,82 \mathrm{~d}(6)$ & $3,91 \mathrm{c}(14)$ & 20,86 b (76) & $2,15 \mathrm{a}$ & $0,27 \mathrm{~b}$ \\
\hline Ac & 2,83 a (11) & 4,56 a (18) & 18,40 c (72) & $1,61 \mathrm{~b}$ & $0,40 \mathrm{a}$ \\
\hline Ses & $1,82 \mathrm{~d}(7)$ & 2,53 e (10) & 16,62 c (68) & $1,39 \mathrm{c}$ & $0,26 \mathrm{~b}$ \\
\hline $\mathrm{Euc}+\mathrm{Ac}$ & $2,56 \mathrm{ab}(13)$ & $2,51 \mathrm{e}(13)$ & $12,83 \mathrm{~d}(65)$ & $0,99 \mathrm{~d}$ & $0,39 \mathrm{a}$ \\
\hline $\mathrm{Euc}+\mathrm{Ses}$ & 2,49 b (7) & $3,48 \mathrm{~d}(10)$ & 23,43 a (68) & $1,41 \mathrm{bc}$ & $0,25 \mathrm{~b}$ \\
\hline $\mathrm{Ac}+\mathrm{Ses}$ & $2,13 \mathrm{c}(7)$ & $4,27 \mathrm{~b}(15)$ & 23,57 a (80) & $2,00 \mathrm{a}$ & $0,27 \mathrm{~b}$ \\
\hline ADVE & 0,62 e (5) & $0,35 \mathrm{f}(3)$ & 6,80 e (57) & $0,58 \mathrm{e}$ & $0,14 \mathrm{c}$ \\
\hline
\end{tabular}

Em que: médias seguidas de mesma letra na coluna não diferem pelo teste $t$ (LSD) a $5 \%$. Valores entre parênteses representam a proporção (\%) de cada fração húmica em relação ao COT. C-FAF = carbono da fração ácidos fúlvicos; $\mathrm{C}-\mathrm{FAH}=$ carbono da fração ácidos húmicos; $\mathrm{C}-\mathrm{HUM}=$ carbono da fração humina; EA = extrato alcalino $=\mathrm{C}-\mathrm{FAH}+$ C-FAF. 
detectaram percentuais de 65 a $71 \%$. Nesse estudo, valores mais elevados foram observados ( 57 a $80 \%$ ) (Tabela 3). O fato de essa fração apresentar maior percentagem de carbono em relação às demais pode estar relacionado à menor estabilidade das frações C-FAF e C-FAH, o que faz com que estas possam ser submetidas a processos de movimentação no perfil, polimerização, ou mineralização, diminuindo sua composição percentual no solo (LEITE et al., 2003; FONTANA et al., 2006). Barreto et al. (2008), em Latossolo, observaram aumentos do C-FAF com a profundidade, assim como Souza e Melo (2003) e Passos et al. (2008).

$\mathrm{O}$ acúmulo de humina no solo, além dos fatores citados acima, também pode estar relacionado ao tamanho da molécula (FONTANA et al. 2006), bem como à sua insolubilidade e resistência à decomposição, ocasionada pela ligação estável existente entre esse componente e a parte mineral do solo (LONGO e ESPÍNDOLA, 2000). De acordo com Souza e Melo (2003), o maior valor de $\mathrm{C}$ na fração humina pode promover uma maior retenção de umidade, melhorias na agregação do solo e maior retenção de cátions. Tal como observado por Pinheiro et al. (2003) e Loss et al. (2010), em Latossolo Vermelho e Argissolo Vermelho-Amarelo, respectivamente, os teores de $\mathrm{C}$ da fração humina, no presente trabalho, acompanham a variação do conteúdo de COT do solo $(\mathrm{r}=0,97, \mathrm{P}=0,0001)$.

Para os valores da relação C-FAH/CFAF foram maiores as áreas de plantios florestais quando comparadas à ADVE, demonstrando a maior proporção de C-FAH nos sistemas de plantios (Tabela 3). Entre os sistemas de plantio, os maiores valores foram encontrados nas áreas com eucalipto e acácia + sesbânia, sendo verificado nesses sistemas o dobro da proporção de C-FAH em detrimento ao C-FAF (Tabela 3). Os menores valores de C-FAH/C-FAF na ADVE (predomínio de gramíneas) indicam que nesse sistema existe maior concentração de C-FAF em relação ao C-FAH. Este padrão é decorrente da intensa adição de COT ao solo por meio da renovação do sistema radicular das gramíneas, favorecendo a decomposição constante da matéria orgânica e, consequentemente, acarretando em maiores teores de carbono da fração mais facilmente biodegradável (BARRETO et al., 2008).

O conteúdo relativo de cada fração da matéria orgânica humificada pode ser usado como indicativo da qualidade do húmus do solo
(MACCALLISTER e CHIEN, 2000). De acordo com Kononova (1966), a relação C-FAH/C-FAF varia de acordo com a fertilidade dos solos, sendo normalmente maior que 1,5 naqueles naturalmente mais férteis, e menor que a unidade nos mais intemperizados. Em condições favoráveis de $\mathrm{pH}$, saturação por bases e drenagem, o aumento do conteúdo do C-FAH é devido ao incremento da atividade microbiana, que promove a síntese de substâncias húmicas mais condensadas (ORLOV, 1998), ou seja, maior proporção de C-FAH em detrimento ao C-FAF (LEITE et al., 2003; LOSS et al., 2010). Este padrão pode ser observado nas áreas com plantios puros e consorciados, com exceção da área de eucalipto + acácia, que apresentou relação menor que a unidade. Os sistemas com valores da relação C-FAH/C-FAF maiores que a unidade indicam a presença de material orgânico mais estável, com consequente aumento do grau de humificação. Dessa forma, tem-se a melhoria da qualidade do solo mesmo em condições favoráveis para rápida mineralização, possivelmente, em razão da maior atividade biológica, promovendo a síntese de substâncias mais condensadas (CANELLAS et al., 2001).

Segundo Barreto et al. (2008), a presença de maiores valores de $\mathrm{C}$ na fração ácidos húmicos indica um estádio mais avançado de estabilização da matéria orgânica, justificável pela maior relação $\mathrm{C}: \mathrm{N}$ nos ácidos fúlvicos quando comparado aos ácidos húmicos, demonstrando maior teor de $\mathrm{N}$ nas frações mais estáveis das substâncias húmicas do solo (SOUZA e MELO 2003).

\section{CONCLUSÕES}

A revegetação de áreas de cava de extração de argila no Norte Fluminense com plantios puros ou consorciados de eucalipto e leguminosas, acarreta em melhorias da fertilidade do solo e dos teores de carbono e nitrogênio totais do solo e do carbono das substâncias húmicas. Aos quatro anos após a revegetação, os sistemas mais indicados, de uma forma geral, para acarretar em aumentos dos teores de COT, $\mathrm{N}$ total, $\mathrm{Mg}$, soma de bases e capacidade de troca catiônica, destacase o plantio de acácia, dentre os plantios puros, e o plantio de eucalipto + sesbânia, dentre os plantios consorciados. Adicionalmente o consórcio eucalipto + sesbânia, apresentou um dos maiores teores $\mathrm{C}$ da fração humina. 


\section{REFERÊNCIAS BIBLIOGRÁFICAS}

ALVARENGA, M. I. N.; DAVIDE, A. C. Características físicas e químicas de um Latossolo Vermelho escuro e a sustentabilidade de agrossistemas. Revista Brasileira de Ciência do Solo, Viçosa, v. 2, p. 933-942, 1999.

ANDRADE, A. G..; COSTA, G. S.; FARIA, S. M. Deposição e decomposição da serapilheira em povoamentos de Mimosa caesalpiniifolia, Acacia mangium e Acacia holosericea com quatro anos de idade em Planossolo. Revista Brasileira de Ciência do Solo, Viçosa, v. 24, p. 777-785, 2000.

ARAÚJO, R. GOEDERT, W. J.; LACERDA, M. P. C. Qualidade de um solo sob diferentes usos e sob cerrado nativo. Revista Brasileira de Ciência do Solo, Viçosa, v. 31, p. 1099-1108, 2007.

AUMOND, J. J.; BALISTIERI, P. R. M. N. Custos de reabilitação ambiental na mineração de matérias primas cerâmicas. In: SIMPÓSIO NACIONAL DE RECUPERAÇÃO DE ÁREAS DEGRADADAS, 3.,1997, Ouro Preto. Anais...Viçosa.

AZEREDO, D.F. Adubação nitrogenada em cana-de-açúcar (Saccharum spp.) em dois solos do estado do Rio de Janeiro. 1997. 190 f. Tese. (Doutorado em Agronomia - Ciência do solo) Universidade Federal Rural do Rio de Janeiro, Seropédica, 1997.

BARRETO, A. C. et al. Fracionamento químico e físico do carbono orgânico total em um solo de mata submetido a diferentes usos. Revista Brasileira de Ciência do Solo, Viçosa, v. 32, p. 1471-1478, 2008. BARROS, N. F. et al. Classificação nutricional de sítios florestais - Descrição de uma metodologia. Revista Árvore, v. 10, n. 2, p. 112-120, 1986.

BATISTA, Q. R. Qualidade química e biológica de uma área degradada pela extração de argila, revegetada com Eucalyptus spp. e sabiá em plantios puros e consorciados. 2006. $45 \mathrm{f}$. Tese. (Doutorado em Produção Vegetal) - Universidade Estadual do Norte Fluminense Darcy Ribeiro UENF, Campos dos Goytacazes, 2006.

BAYER, C.; MIELNICZUK, J. Nitrogênio total de um solo submetido a diferentes métodos de preparo e sistemas de cultura. Revista Brasileira de Ciência do Solo, Viçosa, v. 21, p. 235-239, 1997.

BENITES, V. M.; MADARI, B.; MACHADO, P. L. O. A. Extração e fracionamento quantitativo de substâncias húmicas do solo: um procedimento simplificado e de baixo custo. Rio de Janeiro: Embrapa Solos, 2003. 7 p. (Embrapa Solos. Comunicado Técnico, 16).
CAMPOS, H. Estatística experimental não paramétrica. 3. ed. Piracicaba: Escola Superior de Agricultura Luiz de Queiroz, 1979. 373 p.

CAMPOS, J. B. Efeitos sócio-econômicos e ambientais das indústrias ceramistas 4 e das atividades de extração de argila (Barreiros)em áreas de preservação ambiental: $\mathrm{O}$ caso da região de Maringá. In: SIMPÓSIO NACIONAL DE RECUPERAÇÃO DE ÁREAS DEGRADADAS, 3., Ouro Preto, 1997. Anais...Viçosa: Folha Florestal, 1997. p. 535-543.

CANELLAS, L. P. et al. Organic matter quality in a soil cultivated with perennial herbaceous legumes. Scientia Agricola, Piracicaba, v. 61, p. 53-61, 2004.

CANELLAS, L. P. et al. Distribuição da matéria orgânica e características de ácidos húmicos em solos com adição de resíduos de origem urbana. Pesquisa Agropecuária Brasileira, Brasília, v. 36, p. 1529-1538, 2001.

CARNEIRO, M. A. C. et al. Carbono orgânico, nitrogênio total, biomassa e atividade microbiana do solo em duas cronosseqüências de reabilitação após a mineração de bauxita. Revista Brasileira de Ciência do Solo, v. 32, p. 621-632, 2008.

CHAVES, R. Q.; CORRÊA, G. F. Macronutrientes no sistema solo-Pinus caribaea Morelet em plantios apresentando amarelecimento das acículas e morte de plantas. Revista Árvore, Viçosa, v. 29, p. 691-700, 2005.

CLAESSEN, M. E. C. (Org.). Manual de métodos de análise de solo. 2. ed. rev. atual. Rio de Janeiro: EMBRAPA-CNPS, 1997. 212 p. (EMBRAPACNPS. Documentos, 1).

FONTANA, A. et al. Atributos de fertilidade e frações húmicas de um Latossolo Vermelho no Cerrado. Pesquisa Agropecuária Brasileira, Brasília, v. 41, n. 5, p. 847-853, maio 2006.

FORRESTER, D. I.; BAUHUS, J.; COWIE, A. L. On the success and failure of mixed species tree plantations: lessons learned from a model system of Eucalyptus globulus and Acacia mearnsii. Forest Ecology and Management, Amsterdam, v. 209, n. 1-2, p. 147-155, 2005.

FORRESTER, D. I.; BAUHUS, J.; KHANNA, P. $\mathrm{K}$. Growth dynamics in a mixed-species plantation of Eucalyptus globulus and Acacia mearnsii. Forest Ecology and Management, Amsterdam, v. 193, n. 1-2, p. 81-95, 2004.

FRANCO, A. A. et al. Uso de leguminosas florestais noduladas e micorrizadas como agentes de recuperação e manutenção da vida do solo: 
um modelo tecnológico. In: ESTEVES, F., ed. Oecologia Brasiliensis: estrutura, funcionamento e manejo de ecossistemas. Rio de Janeiro: UFRJ, 1995. p.459-467.

FRANCO, A. A.; FARIA, S. M. The contribution of $\mathrm{N}_{2}$-fixing tree legumes to land reclamation and sustainability in the tropics. Soil Biology Biochemistry, Oxford, v. 9, n. 516, p. 897-903, 1997.

GALIANA, A. et a. Nitrogen fixation estimated by the $15 \mathrm{~N}$ natural abundance method in Acacia mangium Willd. inoculated with Bradyrhizobium sp. and grown in silvicultural conditions. Soil Biology Biochemistry, Oxford., v. 34, p. 351-262, 2002.

GAMA-RODRIGUES, A. C. Ciclagem de nutrientes em sistemas agroflorestais: funcionalidade e sustentabilidade: <http://://www. sbsaf.org.br/anais/2002/trabalhos/003.pdf > Acesso em 25.12.2008.

GAMA-RODRIGUES, E. F.; GAMARODRIGUES, A. C.; BARROS, N. F. Biomassa microbiana de carbono e de nitrogênio de solos sob diferentes coberturas vegetais. Revista Brasileira de Ciência do Solo, Viçosa, v. 21, p. 361-365, 1997. GARAY, I. et al. Comparação da matéria orgânica e de outros atributos do solo entre as plantações de Acacia mangium e Eucalyptus grandis. Revista Brasileira de Ciência do Solo, Viçosa, v. 27, n. 4, p. 705-712, 2003.

GROVE, T. S.; THOMSON, B. D.; ALAJZUK, N. Nutritional physiology of Eucalyptus: uptake, distribution and utilization. In: ATTIWILL, P. M.; ADAMS, M. A. (eds.) Nutrition of Eucalyptus. Australia, 1996. p. 77-108.

KONONOVA, M. M. Soil organic matter. 2nd ed. Oxford: Pergamon Press, 1966.

LEITE, F. P. Relações nutricionais e alterações de características químicas de solo da Região do Vale do Rio Doce pelo cultivo do eucalipto. 2001. 72 p. Tese. (Doutorado em Solos e Nutrição de Plantas) - Universidade Federal de Viçosa, Viçosa, 2001.

LEITE, L. F. C. et al. Estoques totais de carbono orgânico e seus compartimentos em argissolo sob floresta e sob milho cultivado com adubação mineral e orgânica. Revista Brasileira de Ciência do Solo, Viçosa, v. 27, p. 821-832, 2003.

LONGO R. M.; ESPÍNDOLA, C. R. C-orgânico, $\mathrm{N}$-total e substâncias húmicas sob influência da introdução de pastagens (Brachiaria sp.) em áreas de cerrado e floresta amazônica. Revista Brasileira de Ciência do Solo, Viçosa, v. 24, p. 723-729, 2000.
LOSS, A. et al. Quantificação do carbono das substâncias húmicas em diferentes sistemas de uso do solo e épocas de avaliação. Bragantia, v. 69, p. 53-62, 2010.

MACCALLISTER, D. L.; CHIEN, W.L. Organic carbon quantity and forms as influenced by tillage and cropping sequence. Comunications in Soil Science and Plant Analysis, v. 31, p.465-479, 2000. MAFRA, Á. L. et al. Carbono orgânico e atributos químicos do solo em áreas florestais. Revista Árvore, Viçosa, v. 32, p. 217-224, 2008

MENDONÇA, A. V. R. Reabilitação de cavas de extração de argila e tolerância de espécies florestais a salinidade. 2006. 120 f. Tese. (Doutorado em Produção Vegetal) - Universidade Estadual do Norte Fluminense Darcy Ribeiro UENF, Campos dos Goytacazes, 2006.

MENDONÇA, A. V. R. et al. Atributos edáficos de cavas de extração de argila após cultivos puros e consorciados de Eucalyptus spp. e Mimosa caesalpiniifolia Benth (Sabiá) e quantificação da poda de sabiá. Floresta, Curitiba, v. 38, p. 431-443, 2008a.

MENDONÇA, A.V. R. et al. Desempenho de quatro de Eucalyptus spp em plantios puros e consorciados com sabiá (Mimosa caesalpiniifolia Benth) em cava de extração de argila. Revista Árvore, Viçosa, v. 32, p. 395-405, 2008b.

MISHRA, A.; SHARMA, S. D.; KHAN, G. H. Improvement in physical and chemical properties of sodic soil by 3, 6 and 9 years old plantations of Eucalyptus tereticornis: Biorejuvenation of sodic soil. Forest Ecology and Management, Amsterdam, v. 184, p. 115-124, 2003.

MORAES, L. F. D. et al. Características do solo na restauração de áreas degradadas na reserva biológica de Poço das Antas, RJ. Ciência Florestal, Santa Maria, v. 18, p. 193-206, 2008.

MOREIRA, F. M. S.; SIQUEIRA, J. O. Microbiologia e bioquímica do solo. Lavras: Universidade Federal de Lavras, 2002. 625 p.

NOVAIS, R. F.; SMYTH, T. J. Fósforo em solo e planta em condições tropicais. Viçosa, Universidade Federal de Viçosa. 1999. 399 p.

OLIVEIRA, D. M. F. et al. Estudo da contribuição da cobertura vegetal sobre a recuperação de solo degradado pela extração de Bauxita em porto Trombetas-PA. In: SIMPÓSIO NACIONAL RECUPERAÇÃO DE ÁREAS DEGRADADAS, 4., 2000, Blumenau. Anais... Blumenau: Fundação Universidade Regional de Blumenau, 2000.

ORLOV, D. S. Organic substances of russian soils. 
European Journal of Soil Science, Oxford, v. 31, p. 946-953, 1998.

PASSOS, R. R. et al. Substâncias húmicas, atividade microbiana e carbono orgânico lábil em agregados de um latossolo vermelho distrófico sob duas coberturas vegetais. Revista Brasileira de Ciência do Solo, Viçosa, v. 31, p. 1119-1129, 2008.

PAULUCIO, V. O. Qualidade química e biológica de área degradada pela extração de argila, revegetada com eucalipto e leguminosas inoculados com micorrizas. 2007. 106 p. Tese. (Doutorado em Produção Vegetal) - Universidade Estadual do Norte Fluminense 2007Darcy Ribeiro -UENF, Campos dos Goytacazes, 2007.

PILLON, C. N.; MIELNICZUK, J.; MARTIN NETO, L. Ciclagem da matéria orgânica em sistemas agrícolas. Pelotas: Embrapa Clima Temperado, 2004. 27 p.

PINHEIRO, E. F. M. et al. Matéria orgânica em Latossolo Vermelho submetido a diferentes sistemas de manejo e cobertura do solo. Revista Brasileira de Agrociência, Pelotas, v. 9, p. 53-56. 2003.

RAMOS, I. S. et al. Dimensionamento da indústria cerâmica em Campos dos Goytacazes, RJ. In: CONGRESSO BRASILEIRO DE CERÂMICA, 47., 2003, João Pessoa. Anais... São Paulo : TECART, 2003. 1 CD-ROM.

RODRIGUES, L. A. et al. Revegetação de áreas degradadas pela extração de argila no Norte do estado do Rio de Janeiro. Revista Perspectivas, Brasília, v. 5, p. 88-105, 2006

SANTIAGO, A. R. Eucalipto em plantios puros e consorciados com sesbania na reabilitação de cavas de extração de argila. 2005. 77 p. Dissertação (Mestrado em Produção Vegetal) Universidade Estadual do Norte Fluminense Darcy Ribeiro - UENF Campos dos Goytacazes, RJ, 2005. SCHIAVO, J. A ; CANELLAS, L. P ; MARTINS, M. A. Revegetação de cava de extração de argila com Acacia mangium. I- Atributos químicos do solo, ácidos fúlvicos e húmicos. Revista Brasileira de Ciência do Solo, Viçosa, v. 31, p. 1153-1162, 2007a.

SCHIAVO, J. A et al. Revegetação de cava de extração de argila com Acacia mangium. II- Caracterização química da humina. Revista Brasileira de Ciência do Solo, Viçosa, v. 31, p. 1163-1171, 2007b.

SCHIAVO, J. A ; MARTINS, M. A.; RODRIGUES, L. A.. Crescimento de mudas de Acacia mangium, Sesbania virgata e Eucalyptus camaldulensis, inoculadas com fungos micorrízicos, em casa- de-vegetação e em cava-de-extração de argila. Acta Scientiarum. Agronomy, Maringá, v. 32, p. 171-178, 2010.

SCHIAVO, J. A. Revegetação de áreas degradadas pela extração de argila, com espécies micorrizadas de Acacia mangium, Sesbania virgata e Eucalyptus camaldulensis. 2005. Tese 117 p. (Doutorado em Produção Vegetal) Universidade Estadual do Norte Fluminense Darcy Ribeiro - UENF, Campos dos Goytacazes, 2005.

SCHIAVO, J. A. et al. Recovery of degraded areas revegeted with Acacia mangium and Eucalyptus with special reference to organic matter humification. Scientia Agricola, Piracicaba, v. 66, p. 353-360, 2009.

SILVA, C. F. et al. Land degraded by clay extraction reforested with Acacia mangium: Soil fauna as reabilitation indicator. In: ZDRULI, P.; PAGLIAI, M.; KAPUR, S. ;FAZ CANO, ANGEL. (Org.). Land Degradation and Desertification: Assessment, Mitigation and Remediation: Springer, 2010, v. 1, p. 619-626.

SILVA, C. F. et al. Influência do sistema de plantio sobre características dendrométricas e fauna edáfica em área degradada pela extração de argila. Revista Brasileira de Ciência do Solo, Viçosa, v.37; p. 1742-1751, 2013.

SILVA, C. F.; et al. Fungos micorrízicos arbusculares e proteína do solo relacionada à glomalina em área degradada por extração de argila e revegetada com eucalipto e acácia. Ciência Florestal, Santa Maria, v. 22, p.749-761, 2012.

SILVA, C. F. Atributos químicos e biológicos em cavas de extração de argila revegetadas com eucalipto e leguminosas. 2009. $172 \mathrm{f}$. Tese. (Doutorado em Produção Vegetal) - Universidade Estadual do Norte Fluminense Darcy Ribeiro, Campos dos Goytacazes, 2009.

SILVA, J. E.; RESCK, D. V. S.; Matéria orgânica do solo In: VARGAS, M.A.T.; HUNGRIA, M. (Ed.). Biologia dos solos dos cerrados. Planaltina: EMBRAPA-CPAC, 1997. p. 465-524.

SILVA, R. C. et al. Alterações nas propriedades químicas e físicas de um Chernossolo com diferentes coberturas vegetais. Revista Brasileira de Ciência do Solo, Viçosa, v. 31, p. 101-107, 2007.

SNEDECOR, W.; COCHRAN, W. G.. Statistical methods. 8nd ed. Ames: Iowa State University Press, 1989. 502 p.

SOUZA, W. J. O.; MELO, W. J. Matéria orgânica em um Latossolo submetido a diferentes sistemas de produção de milho. Revista Brasileira de 
Ciência do Solo, Viçosa, v. 27, p. 1113-1122, 2003.

STEVENSON, F. J. Humus chemistry, genesis, composition, reaction. New York : John. Wiley \& Sons, 1982. $443 \mathrm{p}$.

STEVENSON, F. J. Humus chemistry; genesis, composition, reactions. New York: John Wiley \& Sons, 1994. $496 \mathrm{p}$.

URQUIAGA, S. et al. Manejo de sistemas agrícolas para o seqüestro de carbono no solo. In: AQUINO, A. M.; ASSIS, R. L. (Org.). Conhecimentos e Técnicas Avançadas para o Estudo dos Processos da Biota no Sistema Solo-Planta. Brasília: Embrapa, 2005. p. 257-273.
VEZZANI, F. M.; TEDESCO, M. J.; BARROS, N. F. Alterações dos nutrientes no solo e plantas em consórcio de Eucalipto e Acácia negra. Revista Brasileira de Ciência do Solo, Viçosa, v. 25, n.1 , p. 225-231, 2001.

WARD, S. C. Soil development on rehabilitated bauxite mines in south-west Australia. Australian Journal Soil Research, Victoria, v. 38, p. 453-464, 2000.

YEOMANS, J. C.; BREMMER, J. M. A rapid and precise method for routine determination of organic carbon in soil. Communication in Soil Science Plant Analysis, Amsterdam, v. 19, p. 1467-1476, 1988. 